\title{
Incidence of Ischemic Colitis and Serious Complications of Constipation Among Patients Using Alosetron: Systematic Review of Clinical Trials and Post-Marketing Surveillance Data
}

\author{
Lin Chang, M.D., ${ }^{1}$ William D. Chey, M.D., F.A.C.G., ${ }^{2}$ Lucinda Harris, M.D., M.Sc., ${ }^{3}$ Kevin Olden, M.D., ${ }^{4}$ \\ Christina Surawicz, M.D., ${ }^{5}$ and Philip Schoenfeld, M.D., M.S.Ed., M.Sc. (Epi) ${ }^{2,6}$ \\ ${ }^{1}$ Center for Neurovisceral Sciences \& Women's Health, Departments of Medicine, UCLA and VA Greater Los \\ Angeles Healthcare Center, Los Angeles, California, ${ }^{2}$ Division of Gastroenterology, University of Michigan \\ School of Medicine, Ann Arbor, Michigan, ${ }^{3}$ Department of Gastroenterology, Mayo Clinic, Scottsdale, Arizona, \\ ${ }^{4}$ Division of Gastroenterology, University of South Alabama School of Medicine, Mobile, Alabama, ${ }^{5}$ Division of \\ Gastroenterology, University of Washington School of Medicine, Seattle, Washington; and ${ }^{6}$ Veterans Affairs \\ Center for Excellence in Health Services Research, Ann Arbor, Michigan
}
BACKGROUND: Ischemic colitis and serious complications of constipation have been reported in association with the use of alosetron, which is approved for women with severe diarrhea-predominant IBS who have failed conventional therapies. This systematic review calculated the incidence of these adverse events in alosetron-using patients in clinical trials and post-marketing surveillance.

METHODS: A panel of experts in epidemiology and functional bowel disorders reviewed clinical trial report forms and FDA MedWatch forms of each reported case of ischemic colitis or serious complications of constipation. Experts were blinded about whether patients used alosetron or placebo. Using pre-specified criteria, experts rated the likelihood of an accurate diagnosis and an association between medication use and adverse events. Cases that were not consistent with the reported diagnosis or not possibly associated with medication use were eliminated from calculation of incidence rates of adverse events.

RESULTS: $\quad$ Pooled data from clinical trials indicate an increased rate of ischemic colitis among alosetron-using patients compared to placebo-using patients $(0.15 \%$ vs $0.0 \%$, respectively, $p=0.03)$, but there was no significant difference in the rate of serious complications of constipation. All (19/19) alosetron-using patients with ischemic colitis had reversible colitis without long-term sequelae. Based on post-marketing surveillance data, the post-adjudication rate of ischemic colitis is 1.1 per 1,000 patient-years of alosetron use and the rate of serious complications of constipation is 0.66 per 1,000 patient-years of alosetron use.

CONCLUSION: The incidence of ischemic colitis and serious complications of constipation is very low and is rarely associated with long-term sequelae or serious morbidity.

(Am J Gastroenterol 2006;101:1069-1079)

\section{INTRODUCTION}

Alosetron is a potent selective antagonist of serotonin 5HT3 receptors $(1,2)$, and it is effective in the treatment of diarrhea-predominant IBS in women based on multiple randomized controlled trials (RCT) (3-9). These RCTs demonstrate that alosetron improves global IBS symptoms and individual symptoms of abdominal discomfort, stool frequency, stool consistency, and urgency. The drug exerts its beneficial effects on IBS symptoms through various actions: (a) increases in colonic compliance (2); (b) motor inhibitory ef- fects in the gastrointestinal tract, resulting in the slowing of small bowel and colonic transit (1); (c) decreases in chloride and water secretion (10); and (d) its central inhibitory effect on "limbic" brain regions, concerned with visceral perception and autonomic circuits, which correlated with IBS symptom improvement (11).

Reports of adverse events, including ischemic colitis and serious complications of constipation, have been reported in association with alosetron use and have created concerns regarding the safety of alosetron. During pre-marketing studies, four cases of possible ischemic colitis were reported in 
alosetron-using patients. After alosetron was introduced in the Spring 2000, 80 cases of ischemic colitis and 100 cases of serious complications of constipation were reported and marketing of alosetron was voluntarily suspended in November 2000. Due to requests from IBS sufferers and patient advocacy groups, the U.S. Food and Drug Administration and GlaxoSmithKline agreed to re-introduce alosetron in November 2002 with a more restrictive indication for the treatment of women with severe diarrhea-predominant IBS who had failed to respond to conventional therapy. After reintroduction in November 2002, use of alosetron was applied through a comprehensive risk management plan.

Disorders of intestinal ischemia include acute mesenteric ischemia (AMI), chronic mesenteric ischemia (CMI) which may be called "intestinal angina," and colonic ischemia which is commonly called "ischemic colitis" $(12,13)$. Colonic ischemia or "ischemic colitis" is the most common type of intestinal ischemia. Although it may result in chronic colitis, colonic stricture, gangrene, or even fulminant universal colitis $(12,13)$, this disorder is usually mild and transient with most patients requiring no specific medical intervention or hospitalization $(12,13)$. In fact, most cases are subclinical and most ischemic colitis patients probably do not come to medical attention because their symptoms are mild and resolve spontaneously (13). Nevertheless, many physicians may inappropriately equate the term "ischemic colitis" with acute mesenteric ischemia or chronic mesenteric ischemia, which are frequently associated with serious morbidity and even mortality $(12,13)$.

Serious complications of constipation may include fecal impaction, intestinal/ileus obstruction, toxic megacolon, and intestinal perforation. According to FDA guidelines, the nature of serious complications of constipation should meet the regulatory definition of "serious adverse events," which indicate that the constipation results in: (a) death; (b) a lifethreatening experience; (c) inpatient hospitalization or prolongation of existing hospitalization; (d) a persistent or significant disability/incapacity; (e) a congenital anomaly/birth defect; or, (f) based on appropriate medical judgment, constipation jeopardizes the patient and medical/surgical intervention is required to prevent one of the outcomes listed in this definition (14). Since alosetron exerts motor inhibitory effects in the gastrointestinal tract and results in decreased propulsion (15), the pharmacologic mechanism for constipation reported in alosetron-using patients is clear.

It is important to quantify the rates and characteristics of serious adverse events associated with alosetron use in order to educate patients and physicians and to guide IBS management. Therefore, the objective of this study was to systematically review clinical trials and post-marketing surveillance data in order to calculate the rate of ischemic colitis and serious complications of constipation in alosetron-using patients and to define the sequelae associated with these adverse events. This review evaluated reported adverse events in on-going as well as previously completed clinical trials and adverse events reported during post-marketing surveil- lance in 2000 as well as since reintroduction in November 2002. In order to complete this process, experts in epidemiology and functional gastrointestinal disorders (L.C., W.D.C., L.H., K.O., C.S.) completed a blinded screening procedure and a blinded adjudication procedure using pre-specified criteria and calculated estimated rates of ischemic colitis and serious complications of constipation among alosetron-using patients.

\section{METHODS}

\section{Literature Search and Study Selection Criteria}

A search of the Medline database from 1995 to 2004 was performed using multiple combinations of the following medical subject heading (MeSH) terms: "colonic diseases, functional"; "irritable bowel syndrome"; "clinical trial"; "alosetron." Review of the EMBASE database from 1995 to 2004 was performed by combining the term "alosetron" with "clinical trial." To access published literature not yet included in the Medline database, Current Contents/Science Edition was searched between 2002 and 2004 combining the key words "alosetron" with "clinical trial." A recursive search of the bibliographies of selected studies was also performed to identify pertinent papers. Study selection criteria were (a) populationalosetron-treated patients; (b) English language; (c) human; and (d) report on frequency of adverse events. Data on study population, dose of medication, duration of treatment, and type of adverse events were extracted by a single researcher. The U.S. Food and Drug Administration web site and reports $(14,16-18)$ were also reviewed for relevant data.

Information about all of the adverse events is in the public domain, and GlaxoSmithKline facilitated obtaining these data. In order to calculate incidence rates from clinical trials and post-marketing surveillance data, GlaxoSmithKline provided data about the number of patients in on-going clinical trials and for alosetron prescriptions. GlaxoSmithKline also provided copies of post-marketing FDA MedWatch forms and clinical trial adverse event form reporting events of ischemic colitis and serious complications of constipation reported through February 2004. GlaxoSmithKline personnel also provided data about the total number of patients treated with alosetron and placebo in GSK-sponsored studies. In order to maintain an "arm's length" relationship and impartial assessment of adverse event data, no further communication between GlaxoSmithKline personnel and study personnel occurred during evaluation of data.

\section{Screening and Adjudication Procedure}

In order to identify all potential cases of ischemic colitis and serious complications of constipation, the following procedures were followed. For post-marketing surveillance cases of serious complications of constipation, any MedWatch form that was coded with the word "constipation" and "serious adverse event" was reviewed. For ischemic colitis, any MedWatch form that was coded with the word "colitis" was 
Table 1. Screening Criteria to Identify Potential Cases of Ischemic Colitis

Probable: Medical history is consistent with ischemic colitis (e.g., abdominal discomfort, hematochezia, and diarrhea) and is supported by the results of colonoscopy (e.g., segmental colitis in the watershed area of the splenic flexure) or other imaging test and/or histological evaluation of a relevant tissue biopsy (e.g., pathologist's report states that mucosal biopsies of colon are consistent with ischemia) and there is no evidence for any more likely diagnosis.

*Undetermined/pending: Positive medical history. Results of colonoscopy, other imaging modalities or tissue histology are pending.

$\dagger$ Insufficient data: Medical history may be positive or inconclusive or inadequate. (e.g., FDA MedWatch form from patient states "I was diagnosed with ischemic colitis" and no other supporting medical information is available.) No data about any imaging modalities or tissue histology were available or were obtained.

${ }^{\dagger}$ Probably not: The results of imaging tests or histology are negative or support a different more probable diagnosis.

If majority of adjudication panel voted for "probably not," then the case was eliminated from further review because ischemic colitis probably did not occur. If majority of adjudication panel voted "insufficient data," then the case was eliminated from further review because inadequate data was available to determine if ischemic colitis actually occurred. Classification of a case as "insufficient data" does not imply the absence of an adverse event.

\#*No cases were classified as "undetermined/pending."

${ }^{\dagger}$ A case was only classified as "insufficient data" if no radiologic or endoscopic studies were performed since the FDA's current adjudication criteria for ischemic colitis requires at least one radiologic or endoscopic study in order to make the diagnosis of ischemic colitis. A case was only classified as "probably not" if hospital records, imaging tests, and histologic results clearly indicated a different diagnosis (e.g., C. dificile colitis proven by colonoscopy and stool studies).

reviewed, regardless of severity of the adverse event (i.e., if the case was not coded as "serious adverse event," even then it was still reviewed). A similar process was followed with adverse event report forms from all on-going and completed clinical trials. Cases of rectal bleeding were not revisited.

\section{Diagnostic Criteria: Assessing the Likelihood of an Accurate Adverse Event Diagnosis}

Criteria for determining if a patient truly had ischemic colitis or a serious complication of constipation (Tables 1 and 2) were established prior to the screening procedure. Based on current FDA adjudication practices, four screening categories were established: probable, undetermined/pending, insufficient data, and probably not. For clinical trial cases, each adverse event case was presented in a blinded fashion (i.e., experts did not know if alosetron or placebo was administered in each case because all references to study medication were deleted). Following presentation of each adverse event case, experts asked questions and discussed the case, then each expert voted by secret ballot about the appropriate screening category for the adverse event case. If the majority of consultants voted "probably not" or "insufficient data," then the case was excluded.

\section{Adjudication Criteria: Assessing the Association between Adverse Events and Medication Use}

Criteria for assessing the association between medication use and adverse events (Table 3) were established prior to the adjudication procedure. Five categories of association were established: definitely related; probably related; possibly related, probably not related; definitely not related. Guidelines to categorize the association between medication use and adverse events were established prior to the adjudication procedure (Table 4). Again, for clinical trial cases, each adverse event case was presented in a blinded fashion (i.e., experts did not know if alosetron or placebo was administered in each case because all references to study medication were deleted). Experts in functional (GI) disorders included members of the ROME III committee on Functional GI Disorders (L.C., W.D.C., K.O.), experts in infectious colitis (C.S.) and functional GI disorders (L.H.). These experts have all published multiple manuscripts and guidelines on the management of functional GI disorders. Following the presentation of each adverse event case, experts asked questions and discussed the case. Experts then completed a checklist about criteria to assess the association between medication use and adverse event and voted by secret ballot about the category of

Table 2. Screening Criteria to Identify Potential Cases of Serious Complications of Constipation

\begin{abstract}
Probable: Medical history is consistent with serious complication of constipation (e.g., patient complained of constipation and met regulatory definition of serious adverse event*) and medical history is supported by hospital/medical records. Results of colonoscopy (or other imaging test) do not identify a more likely diagnosis for patient's symptoms.
\end{abstract}

${ }^{\dagger}$ Undetermined/pending: Positive medical history. Results of hospital/medical records, colonoscopy, or other imaging modalities are pending.

${ }^{\ddagger}$ Insufficient data: Medical history may be positive or inconclusive. No data about hospital/medical records or imaging modalities were available or were obtained.

${ }^{\ddagger}$ Probably not: The results of hospital/medical records or imaging tests are negative or support a different more probable diagnosis.

*Serious Complication of Constipation refers to adverse events of constipation that meet the U.S. Food and Drug Administration definition of a serious adverse event. Serious adverse event is defined as: "death, a life-threatening adverse drug experience, inpatient hospitalization or prolongation of existing hospitalization, a persistent or significant disability/incapacity, a congenital anomaly/birth defect." Serious adverse events also include: "important medical events that may not result in death, be life-threatening, or require hospitalization... [but] based upon appropriate medical judgment, they may jeopardize the patient and may require medical or surgical intervention to prevent one of the outcomes listed in the definition."

†No cases were classified as "undetermined/pending."

¥A case was only classified as "insufficient data" if no medical records were available and the FDA medwatch report came from a non-healthcare professional. A case was only classified as "probably not" if medical records clearly indicated that the case did not rise to the level of serious complication of constipation (e.g., patient did not even require outpatient treatment in an emergency department or another acute care facility). 
Table 3. Criteria for Assessing the Association Between Study Medication Use and Adverse Event (Ischemic Colitis or Serious Complication of Constipation)

1. Were symptoms prompting adverse event report present before the patient started medication?

2. Did the diagnosis of the adverse event occur before the patient started medication?

3. Was the patient on medication long enough for the adverse event to be related to the medication?

4. Was the patient off medication too long for the adverse event to be realistically related to the medication?

5. Was there a realistic competing cause for the adverse event?

6. Was there objective evidence (e.g., pathology, radiographs) to support the diagnosis of the adverse event?

7. Did the symptoms of the adverse event resolve after the therapy was stopped (positive dechallenge)?

8. Did the symptoms of the adverse event return after therapy was reinstituted (positive rechallenge)?

These criteria are GUIDES to determine if the adverse event was definitely related, probably related, possibly related, probably not related, or definitely not related. Ultimately, experts utilized their judgment and clinical expertise to assess the data from a case and decide if medication use was associated with an adverse event.

association between study medication use and adverse event. If all consultants voted "probably not related" or "definitely not related" for a specific case, then that case was excluded (i.e., no possible association between study medication use and adverse event). For clinical trial cases, the blinding code was not broken until after consultants completed voting.

For post-marketing surveillance cases, blinding was not possible. Since all post-marketing surveillance patients obviously used alosetron (i.e., no placebo-using patients among post-marketing surveillance cases), experts might be biased and exclude obvious cases of ischemic colitis or serious complications of constipation. Also, if experts were biased, then they might state no association between medication use and adverse events for every post-marketing surveillance case. Therefore, additional "dummy" cases were added to the screening and adjudication procedure for the post-marketing surveillance cases. These "dummy" cases were intentionally constructed to present a classic history of ischemic colitis or serious complication of constipation and to suggest an association between medication use and adverse event. If experts excluded these "dummy" cases, then this would suggest that consultants were biased and inappropriately excluded obvious adverse event cases. During the adjudication process, all "dummy cases" were considered serious adverse events and rated as "probably associated" with alosetron use, indicating that consultants did not exclude obvious cases of serious adverse events associated with alosetron use during evaluation of post-marketing surveillance cases.

\section{Data Analysis}

Rates (cases per total number of patients treated) of ischemic colitis and serious complications of constipation among clinical trial patients were calculated for all reported cases (i.e., prescreening), all reported cases with an accurate diagnosis of ischemic colitis or serious complication of constipation (i.e., postscreening), and all reported cases of ischemic colitis or serious complications of constipation with possible association to alosetron use (i.e., postadjudication). Event rates (cases per 1,000 patient-years of use) from postmarketing surveillance cases of ischemic colitis and serious complications of constipation were also calculated for pre-screening, post-screening and post-adjudication cases.
Table 4. Category of Association Between Medication and Adverse Event (Ischemic Colitis or Serious Complication of Constipaton)

Definitely related

Exposure and sequence is correct. Symptoms develop after patient starts medication; adverse event diagnosed after patient starts medication; patient on medication long enough for adverse event to be related to medication use; adverse event diagnosed during medication use or shortly after discontinuation of medication.

Positive de-challenge: symptoms of adverse event resolve with withdrawal of medication.

Positive rechallenge: symptoms of adverse event return with reinstitution of medication.

No obvious competing cause that led to adverse event.

Objective evidence to support the diagnosis of an adverse event. Probably related

Exposure and sequence is correct.

Positive de-challenge.

No rechallenge.

No obvious competing cause that led to adverse event.

Objective evidence to support the diagnosis of an adverse event.

Possibly related

Exposure and sequence is correct.

De-challenge ambiguous or negative.

No rechallenge.

No obvious competing cause that led to adverse event.

Objective evidence to support the diagnosis of an adverse event.

Probably not related

Exposure and sequence partly correct.

Competing cause(s) are more likely cause of adverse event.

Ambiguous or conflicting evidence to support the diagnosis of an adverse event.

De-challenge ambiguous or negative.

No re-challenge.

Definitely not related

Exposure and sequence mostly incorrect: symptoms of adverse event develop before patient starts medication; adverse event diagnosed long after patient stops medication; adverse event diagnosed before patient starts medication.

Competing cause(s) are more likely cause of adverse event.

Ambiguous or conflicting evidence to support the diagnosis of adverse event.

De-challenge ambiguous or negative.

No re-challenge.

An adverse event case does not need to fulfill all criteria in a specific category in order to be classified in that category. The criteria in each category are GUIDES to determine if an adverse event was definitely related, probably related, possibly related, probably not related, or definitely not related to medication use. Experts utilized their judgment and clinical expertise to assess the data from a case and decide if use of medication use was associated with an adverse event. 
A priori, sub-group analysis was planned to determine: (a) incidence rates of adverse events in clinical trials and postmarketing surveillance prior to reintroduction in November 2002 and after reintroduction in November 2002; (b) incidence rates for specific types of intestinal ischemia, including colonic ischemia, chronic mesenteric ischemia and acute mesenteric ischemia; and (c) rates of hospitalization, surgery and death associated with ischemic colitis, and serious complications of constipation. Separate analyses of postmarketing adverse event rates prior to and after reintroduction in November 2002 may be important because utilization of alosetron in clinical trials and clinical practice since reintroduction has been restricted to women with severe IBS-D who have failed to respond to conventional therapy. This population may represent a different group of patients compared to patients who used alosetron following its initial approval in 2000 when it was approved for women with IBS-D.

Incidence rates of adverse events from completed/ terminated and on-going clinical trials are pooled to calculate an overall incidence for alosetron-using patients and placebousing patients. Fisher's exact test ( 2 sided) was used to determine if there was a statistically significant difference in the incidence of ischemic colitis or serious complications of constipation between alosetron-using patients and placebo-using patients in clinical trials. For incidence of adverse events during post-marketing surveillance, overall incidence rates and incidence rates per patient-years of alosetron use were calculated assuming that each alosetron prescription represented 1 month of alosetron use.

Demographic data on all cases of ischemic colitis and serious complications of constipation were recorded, including mean age, length of treatment prior to adverse event, gender, and associated nonsteroidal antiinflammatory drugs (NSAIDs) or estrogen/oral contraceptive use. Descriptive statistical data are presented in tabular form. No logistic regression analysis was attempted to determine if any of these factors was associated with adverse events because data on these potential risk factors for the alosetron-using population that did not experience adverse events were not available.

\section{RESULTS}

\section{Characteristics of Selected Studies and Post-Marketing Surveillance Data}

Twenty-six clinical trials $(3-9,17-22)$ satisfied the study selection criteria (Fig. 1). Twenty-four of these trials were completed or terminated at the time of withdrawal of alosetron in November 2000, and two trials are currently on-going. Since an unbalanced randomization schedule was utilized in multiple studies and since some studies were non-randomized safety studies, more study patients received alosetron $(\mathrm{n}=$ $11,874)$ than placebo $(n=3,500)(17)$. After reintroduction of alosetron in June 2002, additional patients were randomized to standard doses of alosetron $(n=441)$ or placebo $(n=178)$ in on-going trials. (Note: since these are blinded on-going tri-

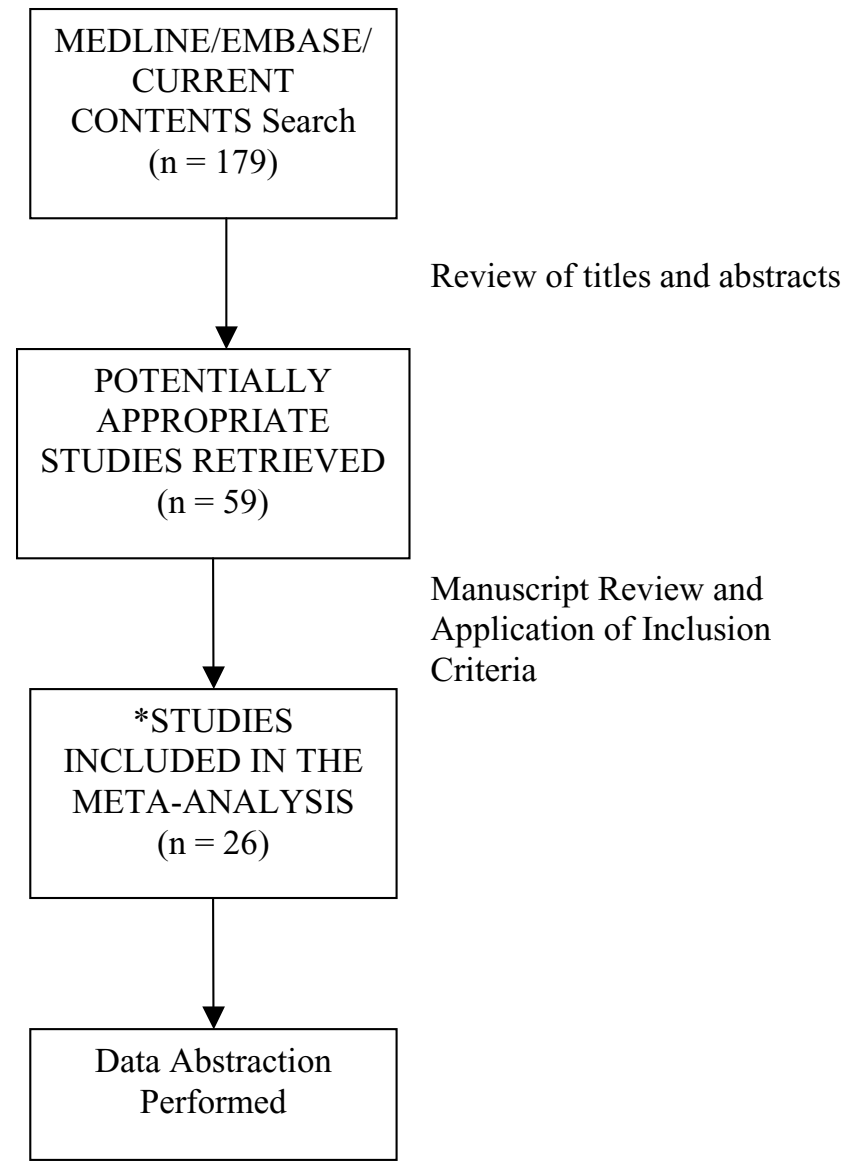

Figure 1. Results of literature search.

als, exact numbers of patients in placebo and alosetron groups were unavailable. We estimated the number of patients using alosetron and placebo based on the number of patients enrolled by February 6, 2004 and based on the randomization schedule.)

From February 2000 through November 2000, 316,882 patients received 586,000 prescriptions, producing 48,829 patient-years of alosetron use during the initial postmarketing surveillance period (17). After reintroduction of alosetron in November 2002 through January 2003, 12,032 patients received 39,163 prescriptions, producing another 3,263 patient-years of use (18). These data are higher than previous estimates since they account for non-retail sales to mail-order pharmacies, hospitals, and clinics, and retail sales to chain pharmacies, independent pharmacies, and pharmacies in supermarkets.

\section{Incidence of Ischemic Colitis in Clinical Trials}

Tables 5 and 6 lists the pre-screening, post-screening and post-adjudication incidence of ischemic colitis from clinical trials before and after June 2002 (date of reintroduction of alosetron). Overall, there were 20 possible cases of ischemic colitis in alosetron-using patients in clinical trials, and one case was eliminated during the screening process because it did not meet the criteria for diagnosis of ischemic 
Table 5. Incidence of Ischemic Colitis During Clinical Trials Prior to November 2000 (Prior to FDA Approval for Reintroduction of Alosetron)

\begin{tabular}{lccc}
\hline & $\begin{array}{c}\text { Alosetron } \\
(\mathrm{n}=11,874)\end{array}$ & $\begin{array}{c}\text { Placebo } \\
(\mathrm{n}=3500)\end{array}$ & $p$ Value \\
\hline $\begin{array}{l}\text { All reported cases } \\
\quad \text { Prescreening) }\end{array}$ & $18(0.15 \%)$ & $2(0.06 \%)$ & 0.41 \\
$\begin{array}{c}\text { All reported cases with } \\
\text { accurate Dx (Postscreening) }\end{array}$ & $17(0.14 \%)$ & $0(0.0 \%)$ & 0.03 \\
$\begin{array}{c}\text { All reported cases with } \\
\text { accurate DX and possible } \\
\text { association with alosetron } \\
\text { use (Postadjudication) }\end{array}$ & $17(0.14 \%)$ & $0(0.0 \%)$ & 0.03 \\
\hline
\end{tabular}

Statistical comparison based on Fisher's exact test (two-sided).

colitis. Of the remaining 19 cases, all were considered at least possibly associated with alosetron use. The mean age was $50 \mathrm{yr}, 100 \%$ were women, and $53 \%$ used oral contraceptives or hormone replacement therapy concurrently. Of total, $42.1 \%$ suffered ischemic colitis within 1 wk of alosetron use, while an additional $21.0 \%$ suffered ischemic colitis on days 8-30 of alosetron use (Table 7). Of the two possible cases of ischemic colitis in placebo-using patients, both cases were eliminated during the screening process because they did not meet the criteria for the diagnosis of ischemic colitis. A statistically significant increase in the post-adjudication incidence of ischemic colitis for alosetron-using patients versus placebo-using patients was apparent after pooling of data from all trials $(0.15 \%$ vs $0.0 \% ; p=0.03)$. Based on 19 total cases of ischemic colitis during 2,991 total patient-years of alosetron use in clinical trials, the rate of ischemic colitis is 6.4 cases per 1,000 patient-years compared to 0.0 case per 1,000 patient-years of placebo use.

Among the 19 cases of ischemic colitis reported in alosetron-using patients in clinical trials, all cases were reversible colitis without long-term sequelae (Fig. 8). There were no cases of acute or chronic mesenteric ischemia. Nine of the ischemic colitis patients were hospitalized, none had abdominal surgery, and there were no deaths.

Table 6. Incidence of Ischemic Colitis During Clinical Trials After June 2002 (After FDA Approval for Re-Introduction of Alosetron)

\begin{tabular}{llll}
\hline & $\begin{array}{c}* \text { Alosetron } \\
(\mathrm{n}=441)\end{array}$ & $\begin{array}{l}\text { *Placebo } \\
(\mathrm{n}=178)\end{array}$ & $p$ Value \\
\hline $\begin{array}{l}\text { All reported cases } \\
\quad \text { Prescreening) }\end{array}$ & $2(0.4 \%)$ & $0(0.0 \%)$ & 1.00 \\
$\begin{array}{l}\text { All reported cases with } \\
\text { accurate IC }\end{array}$ & $2(0.4 \%)$ & $0(0.0 \%)$ & 1.00 \\
$\begin{array}{l}\text { DX(Postscreening) } \\
\text { All reported cases with } \\
\text { accurate IC DX and possible } \\
\text { association with alosetron } \\
\text { use (Postadjudication) }\end{array}$ & $2(0.4 \%)$ & $0(0.0 \%)$ & 1.00 \\
& & & \\
\hline
\end{tabular}

Does not include patients in alosetron clinical trials that use prn doses of medication. *These data come from on-going, double-blind trials. Exact numbers of patients in alosetron arm and placebo arm have not been unblinded. The number of patients in the alosetron and placebo arm reflect estimates based on the total number of patients enrolled in these trials and the randomization schedules used.
Table 7. Demographic Data for Alosetron-Using Patients Suffering Ischemic Colitis in Completed and On-Going Clinical Trials $(\mathrm{n}=$ 19)

\begin{tabular}{lc}
\hline Demographic Characteristics & \\
\hline Mean age & 50.0 \\
Male & $0 \%$ \\
Female & $100 \%$ \\
$\%$ on NSAIDs & 16 \\
$\%$ on estrogen or oral contraceptives & 53 \\
$\%$ on anti-diarrheal medication & 11 \\
$\%$ on narcotic medication & 5 \\
Time on medication until symptoms is 1-7 days & $42.1 \%$ \\
Time on medication until symptoms is 8-30 days & $21.0 \%$ \\
Time on medication until symptoms is 31-90 days & $21.0 \%$ \\
Time on medication until symptoms is greater & $15.8 \%$ \\
$\quad$ than 90 days & \\
\hline
\end{tabular}

\section{Incidence of Serious Complications of Bowel Dysfunction in Clinical Trials}

Tables 8 and 9 list the pre-screening, post-screening and postadjudication incidence of serious complications of constipation from clinical trials before November 2000 and after June 2002 (date of reintroduction of alosetron). Overall, there were 14 possible cases of serious complication of bowel dysfunction in alosetron-using patients in clinical trials, and three cases were eliminated during the screening process because they did not meet diagnostic criteria. Of the remaining 11 cases, one was eliminated because no association with study medication could be demonstrated. The mean age was $50.4 \mathrm{yr}$, $100 \%$ were women, $10 \%$ used anti-diarrheal medication concurrently and $10 \%$ used narcotics concurrently. No cases occurred within the first 7 days of use, although $40 \%$ of cases occurred on days 8-30 of alosetron use (Table 10). Of the two possible cases of serious complications of bowel dysfunction in placebo-using patients, both cases met diagnostic criteria for serious complications of bowel dysfunction, but one was eliminated because no association with study medication could be demonstrated. There was no significant difference in the rate of serious complications of bowel dysfunction between placebo-using patients and alosetron-using patients

Table 8. Incidence of Serious Complications of Constipation During Clinical Trials Prior to November 2000 (Prior to FDA Approval for Reintroduction of Alosetron)

\begin{tabular}{|c|c|c|c|}
\hline & $\begin{array}{c}\text { Alosetron } \\
(\mathrm{n}=11,874)\end{array}$ & $\begin{array}{c}\text { Placebo } \\
(\mathrm{n}=3,500)\end{array}$ & $p$ Value \\
\hline $\begin{array}{l}\text { All reported cases } \\
\text { (Prescreening) }\end{array}$ & $12(0.10 \%)$ & $2(0.06 \%)$ & 0.69 \\
\hline $\begin{array}{l}\text { All reported cases with } \\
\text { accurate DX } \\
\text { (Postscreening) }\end{array}$ & $10(0.084 \%)$ & $2(0.06 \%)$ & 1.00 \\
\hline $\begin{array}{l}\text { All reported cases with } \\
\text { accurate DX and possible } \\
\text { association with alosetron } \\
\text { use (Postadjudication) }\end{array}$ & $9(0.076 \%)$ & $1(0.03 \%)$ & 1.00 \\
\hline
\end{tabular}

Statistical comparison based on Fisher's exact test (two-sided). 
Table 9. Incidence of Serious Complications of Constipation During Clinical Trials After June 2002 (After FDA Approval for Reintroduction of Alosetron)

\begin{tabular}{lccc}
\hline & $\begin{array}{c}\text { Alosetron } \\
(\mathrm{n}=441)\end{array}$ & $\begin{array}{c}\text { Placebo } \\
(\mathrm{n}=178)\end{array}$ & $p$ Value \\
\hline $\begin{array}{c}\text { All reported cases } \\
\text { (Prescreening) }\end{array}$ & $2(0.4 \%)$ & $0(0.0 \%)$ & 1.00 \\
$\begin{array}{c}\text { All reported cases with } \\
\text { accurate DX (Postscreening) }\end{array}$ & $1(0.2 \%)$ & $0(0.0 \%)$ & 1.00 \\
$\begin{array}{c}\text { All reported cases with } \\
\text { accurate DX and possible } \\
\text { association with alosetron } \\
\text { use (Postadjudication) }\end{array}$ & $1(0.2 \%)$ & $0(0.0 \%)$ & 1.00 \\
\hline
\end{tabular}

Does not include patients in alosetron clinical trials that use prn doses of medication.

in clinical trials. Based on 10 total cases of serious complications of constipation during 2,991 total patient-years of alosetron use in clinical trials, the rate of serious complications of constipation is 3.3 cases per 1,000 patient-years compared to 1.0 case per 1,000 patient-years of placebo use.

Among the 10 cases of serious complications of bowel dysfunction in aloseton-using patients, all were hospitalized, one underwent abdominal surgery and none died. One case of serious complications of constipation was associated with ischemic colitis occurring secondary to constipation.

\section{Incidence of Ischemic Colitis in Post-Marketing Surveillance}

Table 11 lists the pre-screening and post-adjudication incidence of ischemic colitis from post-marketing surveillance. There was no significant difference in rates of ischemic colitis during initial use of alosetron (prior to November 2000) compared to post-reintroduction (after November 2002). Of 89 possible cases of ischemic colitis, 35 cases were eliminated during the screening process. The majority $(>90 \%)$ of these cases were eliminated because there was no documentation of a medical evaluation, although a minority of cases were eliminated because they did not meet diagnostic criteria due to the absence of diagnostic testing (e.g., no endoscopic or radiologic imaging of colon). Of the remaining 54 cases, one case was eliminated because reviewers determined that there

Table 10. Demographic Data for Alosetron-Using Patients Suffering Serious Complications of Constipation in Completed and On-Going Clinical Trials $(\mathrm{n}=10)$

\begin{tabular}{lc}
\hline Demographic Characteristics & \\
\hline Mean age & 50.4 \\
Male & 0 \\
Female & $100 \%$ \\
\% on NSAIDs & $20 \%$ \\
\% on estrogen or oral contraceptives & $40 \%$ \\
\% on anti-diarrheal medication & $10 \%$ \\
\% on narcotic medication & $10 \%$ \\
Time on medication until symptoms is 1-7 days & $0 \%$ \\
Time on medication until symptoms is 8-30 days & $40 \%$ \\
Time on medication until symptoms is 31-90 days & $50 \%$ \\
Time on medication until symptoms is greater than 90 days & $10 \%$ \\
\hline
\end{tabular}

was no possible association with alosetron use. The postadjudication rate of ischemic colitis in the post-marketing surveillance population is estimated at 1.0 case per 1,000 patient-years. In these cases, the mean age was $53.5 \mathrm{yr}, 98 \%$ were women, and $42 \%$ used oral contraceptives or hormone replacement therapy concurrently (Table 12). Ischemic colitis occurred within 7 days of use in $28 \%$ of patients and during days $8-30$ in $21 \%$ of patients (Table 12). Among the 54 cases of ischemic colitis reported in post-marketing surveillance, 52 were cases of reversible colitis with one case of colonic stricture and one case of gangrene. Thirty-six of these patients were hospitalized with three undergoing surgery and no deaths.

In post-marketing surveillance, there were also 12 reported cases of acute or chronic mesenteric ischemia in the previous marketing cycle, although four of these cases were eliminated during screening because they did not meet diagnostic criteria and another three were eliminated because reviewers determined that there was no possible association with alosetron use. Of the remaining five patients, all were hospitalized and underwent surgery and one died. According to previous review by FDA officials, all five patients had complicated medical histories with other risk factors for vascular disease and the potential association with alosetron is unclear. All five of these cases occurred prior to reintroduction of alosetron in November 2002.

\section{Incidence of Serious Complications of Constipation in Post-Marketing Surveillance}

Table 11 also lists the pre-screening and post-adjudication incidence of serious complications of constipation from post-marketing surveillance. Again, there was no significant difference in rates of serious complications of constipation during initial use of alosetron (prior to 2002) compared to post-reintroduction (after 2002). Of 108 possible cases of serious complication of bowel dysfunction, 74 were eliminated during the screening process because they did not meet diagnostic criteria. The majority ( $>90 \%$ ) of these cases were eliminated because there was no documentation of medical evaluation, although a minority of cases were eliminated because they did not meet diagnostic criteria for a serious complication of constipation (e.g., patient with constipation who did not require even outpatient treatment in an emergency department or other acute care facility). Of the remaining 34 cases, three were eliminated because reviewers determined that no association with alosetron could be demonstrated. Of the remaining 31 cases, the mean age was $56.4,97 \%$ were women, $42 \%$ of patients used oral contraceptives or hormone replacement therapy concurrently, and $26 \%$ of cases occurred within 7 days of treatment and $32 \%$ occurred during days 8-30 of treatment (Table 13). The post-adjudication rate of serious complications of bowel dysfunction in the post-marketing surveillance population is estimated at 0.6 cases per 1,000 patient-years (Table 11). Among the 31 cases of serious complications of constipation, 29 were hospitalized, 10 had surgery, and two deaths were associated with 
Table 11. Incidence of Ischemic Colitis and Serious Complications of Constipation During Post-Marketing Surveillance (Reported in Rate per 1,000 Patient-Years of Use)

\begin{tabular}{|c|c|c|c|}
\hline & $\begin{array}{c}\text { Before June } 2002 \\
(\mathrm{n}=48,829 \text { pt-yrs })\end{array}$ & $\begin{array}{l}\text { After June } 2002 \\
(\mathrm{n}=3263 \text { pt-yrs })\end{array}$ & $\begin{array}{c}\text { Total } \\
(\mathrm{n}=52,092 \mathrm{pt}-\mathrm{yrs}) \\
\end{array}$ \\
\hline Ischemic colitis (all reported cases/prescreening) & 1.7 per 1,000 pt-yrs & 2.5 per 1,000 pt-yrs & 1.7 per 1,000 pt-yrs \\
\hline $\begin{array}{l}\text { Ischemic colitis (all reported cases with accurate Dx and } \\
\text { possible association with alosetron use/postadjudication) }\end{array}$ & 0.96 per 1,000 pt-yrs & 1.53 per 1,000 pt-yrs & 1.0 per 1,000 pt-yrs \\
\hline $\begin{array}{l}\text { Serious complication of constipation (all reported } \\
\text { cases/prescreening) }\end{array}$ & 2.0 per 1,000 pt-yrs & 2.5 per 1,000 pt-yrs & 2.1 per 1,000 pt-yrs \\
\hline $\begin{array}{l}\text { Serious complications of constipation (all reported cases } \\
\text { with accurate Dx and possible association with alosetron } \\
\text { use/postadjudication) }\end{array}$ & 0.59 per 1,000 pt-yrs & 0.61 per 1,000 pt-yrs & 0.60 per $1,000 \mathrm{pt}-\mathrm{yrs}$ \\
\hline
\end{tabular}

these adverse events. Three cases of serious complication of constipation were associated with secondary ischemic colitis (i.e., ischemic colitis occurred due to constipation causing compression of colonic mucosa).

\section{DISCUSSION}

This study represents the first external, blinded, systematic review of ischemic colitis and serious complications of constipation in patients using alosetron. This review of clinical trials and post-marketing surveillance data estimates the incidence of ischemic colitis and serious complications of constipation in alosetron-using patients and defines the sequelae associated with these adverse events. Pooled clinical trial data demonstrate an increased risk of ischemic colitis among alosetron-using patients $(0.15 \%$ vs $0.0 \%, p=0.03)$, but do not demonstrate an increase in serious complications of constipation. Notably, all clinical trial patients diagnosed with ischemic colitis suffered a transient colitis without long-term sequelae. Post-marketing surveillance data estimates that the rate of ischemic colitis is 1.0 per 1,000 patient-years of alosetron use and the rate of serious complications of constipation is 0.60 per 1,000 patient-years of alosetron use. With these data, women with severe diarrhea-predominant IBS who are considering using alosetron may be appropriately educated about the risks associated with alosetron use.

Table 12. Demographic Data for Alosetron-Using Patients Suffering Ischemic Colitis in Post-Marketing Surveillance $(\mathrm{n}=53)$

\begin{tabular}{lc}
\hline Demographic Characteristics & \\
\hline Mean age & 53.5 \\
Male & $2 \%$ \\
Female & $98 \%$ \\
\% on NSAIDs & 16 \\
\% on estrogen or oral contraceptives & 42 \\
\% on anti-diarrheal medication & 2 \\
\% on narcotics & 2 \\
Time on medication until symptoms is 1-7 days & $28.4 \%$ \\
Time on medication until symptoms is 8-30 days & $26.4 \%$ \\
Time on medication until symptoms is 31-90 days & $11.3 \%$ \\
Time on medication until symptoms is greater & $20.8 \%$ \\
$\quad$ than 90 days & \\
Time on medication until symptoms unknown & $13.2 \%$
\end{tabular}

When educating prospective patients about the risk of ischemic colitis associated with alosetron use, two issues should be noted. First, intestinal ischemia associated with alosetron use is virtually always colonic ischemia, which is transient and rarely associated with no long-term sequelae or the need for hospitalization. Acute mesenteric ischemia and chronic mesenteric ischemia, which are associated with significant morbidity and mortality, have not been reported in alosetron-using patients in clinical trials nor during postmarketing since reintroduction. Second, alosetron-associated ischemic colitis is infrequently $(<10 \%)$ associated with severe constipation in clinical trials and in post-marketing surveillance. Consequently, severe constipation does not appear to be a requisite for the development of ischemic colitis.

Recent studies (23-26) indicate that IBS patients are more likely to be diagnosed with ischemic colitis compared to healthy controls (Table 14). The precise explanation for this association is unclear, although some symptoms of ischemic colitis and IBS (e.g., abdominal discomfort) are similar, which may make it difficult to rule out a random association of two conditions with similar clinical expression in some patients. For example, it is conceivable that some ischemic colitis patients are initially misdiagnosed as suffering from IBS (27). However, even patients who carry the IBS diagnosis for greater than $1 \mathrm{yr}$ have a five-fold increase in the subsequent diagnosis of ischemic colitis compared to healthy

Table 13. Demographic Data for Aloestron-Using Patients Suffering Serious Complications of Constipation during Post-Marketing Surveillance $(\mathrm{n}=31)$

Demographic Characteristics

\begin{tabular}{lc}
\hline Mean age & 56.4 \\
Male & $3 \%$ \\
Female & $97 \%$ \\
$\%$ on NSAIDs & $19 \%$ \\
$\%$ on estrogen or oral contraceptives & $42 \%$ \\
$\%$ on anti-diarrheal medication & $10 \%$ \\
$\%$ on narcotic medication & $19 \%$ \\
Time on medication until symptoms is 1-7 days & $25.8 \%$ \\
Time on medication until symptoms is 8-30 days & $32.3 \%$ \\
Time on medication until symptoms is 31-90 days & $12.9 \%$ \\
Time on medication until symptoms is greater & $16.1 \%$ \\
$\quad$ than 90 days & \\
Time on medication until symptoms unknown & $12.9 \%$
\end{tabular}


Table 14. Incidence of Ischemic Colitis in IBS and Non-IBS Populations (per 1,000 Patient-Years)

\begin{tabular}{lcc}
\hline Source & Non-IBS & IBS \\
\hline Medi-Cal: 1995-2002 (25) & 0.5 & 1.8 \\
United Health Care: 1995-1999 (24) & 0.01 & 0.4 \\
CORI database: 2000-2003 & 0.2 & 0.9 \\
\hline
\end{tabular}

controls (27), suggesting that misdiagnosis is not the sole explanation for the association between ischemic colitis and IBS. Second, IBS patients do undergo colonoscopy more frequently than healthy controls (28), which may create an ascertainment bias. For example, an IBS patient who is followed by a gastroenterologist may be more likely to get an urgent colonoscopy for abdominal discomfort with hematochezia and be diagnosed with ischemic colitis compared to a healthy individual with similar symptoms who would have their colonoscopy delayed until after referral from a primary care physician or might not even seek medical care if the symptoms are transient and self-limited. Third, pathophysiologic abnormalities in IBS patients may actually increase the risk of ischemic colitis. Recent data demonstrate that both ulcerative colitis and IBS are associated with molecular changes in serotonergic signaling mechanisms (29). Since serotonin signaling could affect colonic mucosal circulation, it is conceivable that this might account for the increased incidence of ischemic colitis in IBS patients (30).

Though the etiology of ischemic colitis in alosetron-using IBS patients is unclear, several explanations are possible. First, 5-HT3 receptor antagonists may allow available serotonin to interact with other serotonin receptor sub-types (5HT1 receptors) known to influence vascular perfusion in animals with damaged endothelium due to disease (30). Second, 5-HT released from enterochromaffin cells is thought to play a role in the coordination of motor activity and mucosal blood flow in the intestine by activating sensory myenteric and/or submucosal neurons which in turn activate vasodilatory neurons (31). Thus, it is conceivable that blockade of 5-HT3 receptors interferes with the protective mechanisms of mucosal and submucosal vasodilatation. Third, the development of severe constipation with associated colonic distention and local vascular compression may infrequently contribute to the development of ischemic colitis. It is notable that only three cases of ischemic colitis in post-marketing surveillance and one case from clinical trials were associated with severe constipation. Finally, alosetron-associated ischemic colitis may not represent classic ischemic colitis but rather it may reflect a different type of drug-associated colitis similar to NSAID-associated colitis. Certainly, there were no consistent pathologic findings in alosetron-using patients diagnosed with ischemic colitis and endoscopic abnormalities were reported to affect sections of the colon other than the classic "watershed" areas of the splenic flexure and sigmoid colon.

Risk factors for colonic ischemia include increasing age, female gender, cardiovascular disease, vascular surgery, predisposition to thromboembolism, and co-morbid illnesses in- cluding IBS and COPD $(13,23,32)$. A logistic regression analysis to search for risk factors associated with alosetronassociated ischemic colitis is beyond the scope of the study because it would require more complete demographic data on alosetron-using patients who did not suffer from these events. Nevertheless, our demographic data clearly indicate that a substantial percentage ( $>25 \%$ ) of ischemic colitis cases and serious complications of constipation cases occur within the first 7 days of use and the majority of these adverse events occur within the first 30 days. Therefore, both patients and physicians should be particularly vigilant about monitoring for symptoms suggestive of ischemic colitis or severe constipation during the first 30 days of treatment. This fact emphasizes the need for education of patients as required by the alosetron risk management program: early recognition and management of constipation and ischemic colitis should reduce the frequency of sequelae from adverse events. In fact, there have been no surgeries, mesenteric ischemia, or deaths among alosetron-using patients since reintroduction in November 2002.

The screening and adjudication process was designed to minimize the possibility that true cases of alosetronassociated adverse events would be excluded. The screening criteria were very broad and minimal medical history was required to confirm the diagnosis of adverse events. During the adjudication process, the primary reason for excluding possible cases of ischemic colitis or severe constipation was absent or insufficient medical data (e.g., An FDA MedWatch form that states "my sister used alosetron and she was diagnosed with ischemic colitis. No other information available"). The adjudication procedure attempted to minimize bias through several mechanisms: (a) experts were blinded about whether patients used alosetron or placebo for clinical trial cases; (b) criteria to determine the association between study medication use and adverse events were objective and specified prior to the screening procedure and adjudication procedure; (c) for post-marketing surveillance cases, "dummy" patients were added to ensure that the experts did not perform a biased adjudication (i.e., automatically stating no association between study medication and adverse events); and (d) if even a single expert stated a possible association between study medication use and adverse event, then that case was included in the post-adjudication calculation of adverse event incidence rates. With this adjudication procedure, only adverse event cases that could not be associated with study medication were excluded.

Our study has several limitations. First, adverse events associated with medication use may be under-reported, particularly during post-marketing surveillance. Therefore, data from clinical trials are more likely to reflect the true incidence rate of adverse events than data obtained during postmarketing surveillance. Our data reinforce this hypothesis since adverse events were reported more frequently in the clinical trials than during post-marketing surveillance. However, we think that under-reporting for alosetron-associated adverse events may have been minimized due to the extensive 
publicity in the lay media about alosetron-associated ischemic colitis. Second, during the adjudication of postmarketing surveillance reports of serious adverse events, we eliminated reports with insufficient data to make a diagnosis of ischemic colitis or serious complications of constipation. Nevertheless, some of these patients may have truly had a serious adverse event. Therefore, we provided "pre-screening" rates and "post-adjudication" rates for serious adverse events in Table 13, which provides a high and low estimate of the rate of serious adverse events during post-marketing surveillance. Third, the definitions of ischemic colitis and serious complications of constipation and the screening criteria (Tables 1 and 2) are vague, but these definitions and screening criteria were adapted from current FDA adjudication criteria. Future studies may benefit from using more precise definitions and screening criteria.

In conclusion, an increased incidence of ischemic colitis among alosetron-using patients versus placebo-using patients was demonstrated in pooled analysis of clinical trial data $(0.15 \%$ vs $0.0 \%, p=0.03)$. Post-marketing surveillance data estimates that the rate of ischemic colitis is 1.0 per 1,000 patient-years of alosetron use, although this figure may slightly underestimate the rate since all cases of ischemic colitis reported during post-marketing use may not have been reported. All clinical trial patients with ischemic colitis suffered a transient colitis without long-term sequelae. The frequency of serious complications of bowel dysfunction is similar among alosetron-using patients and placebo-using patients in clinical trials, and the post-marketing surveillance rate of serious complications of constipation is only 0.60 per 1,000 patient-years of use. Although risk factors for alosetron-associated adverse events have not yet been clearly identified, the majority of adverse events occured within 30 days of initiating therapy. Therefore, patients and physicians should be particularly attentive during this time period. These data should facilitate education of health care providers and patients who are considering alosetron for management of severe IBS-D. Further studies to determine possible risk factors for alosetron-associated ischemic colitis, to determine possible mechanisms of action for this insult, and to explore the possibility that alosetron causes a previously undescribed form of drug-induced colitis are warranted. Data from such studies should help clinicians better identify those patients at significantly increased risk for suffering these adverse events.

\section{ACKNOWLEDGMENTS}

Potential Conflicts of Interest: Drs. Chang, Chey, Harris, Olden, Surawicz, and Schoenfeld have worked as consultants and/or speakers bureau for GlaxoSmithKline and Novartis Pharmaceuticals Corporation. Drs. Chang, Chey, and Olden have worked as consultants for Solvay Pharmaceuticals. Dr. Chey has served as a consultant for Takeda and Vela Pharmaceuticals. This project was funded through an unrestricted educational grant from GlaxoSmithKline.

\section{STUDY HIGHLIGHTS}

\section{What Is Current Knowledge}

- Alosteron is effective in a proportion of women with diarrhea predominant irritable bowel syndrome (IBS).

- Alosteron is associated with rare serious adverse events related to ischemic colitis and constipation (fecal impaction, ileus, toxic megacolon, perforation).

- The incidence of serious adverse events is unknown.

\section{What Is New Here}

- A systematic review of clinical trials suggests ischemic colitis and serious complications of constipation occurred at a rate of 6.4 and 3.3 per 1000 patient years respectively in patients allocated to alosetron.

- Post-marketing surveillance gave lower estimates of risk.

- There were no deaths and all cases of ischemic colitis in clinical trials were reversible.

Reprint requests and correspondence: Philip Schoenfeld, M.D., VA Ann Arbor Healthcare Systems (111D), 2215 Fuller Road, Ann Arbor, MI 48105.

Received December 23, 2004; accepted May 10, 2005.

\section{REFERENCES}

1. Forster JM, Houghton LA, Whorwell PJ. Alosetron slows colonic transit in patients with irritable bowel syndrome. Gastroenterology 1996;110:A630. [abstract]

2. Delvaux M, Louvel D, Mamet JP, et al. Effect of alosetron on responses to colonic distension in patients with irritable bowel syndrome. Aliment Pharmacol Ther 1998;12:849-55.

3. Camilleri M, Mayer E, Drossman D, et al. Improvement in pain and bowel function in female irritable bowel syndrome patients with alosetron, a 5HT3 receptor antagonist. Aliment Pharmacol Ther 1999;13:1149-51.

4. Jones R, Holmann G, Rodrigo L, et al. Alosetron relieves pain and improves bowel function compared with mebeverine in female non-constipated irritable bowel syndrome patients. Aliment Pharmacol Ther 1999;13:1419-27.

5. Camilleri M, Northcutt AR, Kong S, et al. The efficacy and safety of alosetron in female patients with irritable bowel syndrome: A randomized, placebo controlled study. Lancet 2000;355:1035-40.

6. Lembo T, Wright RA, Bagby B, et al. Alosetron controls bowel urgency and provides global symptom improvement in women with diarrhea-predominant irritable bowel syndrome. Am J Gastroenterol 2001;96:2662-70.

7. Bardhan K, Bodemar G, Geldor H, et al. A double-blind placebo-controlled study to evaluate the efficacy of alosetron in the treatment of irritable bowel syndrome. Aliment Pharmacol Ther 2000;14:23-4.

8. Lembo A, Olden K, Ameen V, et al. Effect of alosetron on bowel urgency and global symptoms in women with severe diarrhea-predominant IBS: Analysis of two controlled trials. Clin Gastroenterol Hepatol 2004;2:675-82.

9. Chey WD, Chey WY, Heath AT, et al. Long-term safety and efficacy of alosetron in women with severe diarrhea- 
predominant irritable bowel syndrome. Am J Gastroenterol 2004;99:2195-203.

10. Bearcroft CP, Andre EA, Farthing MJ. In vivo effects of the 5-HT3 antagonist alosetron on basal and cholera toxininduced secretion in the human jejunum: A segmental perfusion study. Aliment Pharmacol Ther 1997;11(6):110914.

11. Berman SM, Chang L, Suyenobu B, et al. Condition specific deactivation of brain regions by $5 \mathrm{HT} 3$ receptor antagonist alosetron. Gastroenterology 2002;123(4):969-77.

12. American Gastroenterological Association Medical Position Statement: Guidelines on intestinal ischemia. Gastroenterology 2000;118:951-3.

13. Brandt LJ, Boley SJ. AGA technical review on intestinal ischemia. Gastroenterology 2000;118:954-68.

14. Code of Federal Regulations, Title 21 Food and Drugs, Part 312, Section 312.32 IND Safety Reports.

15. Viramontes BE, Camilleri M, McKinzie, et al. Genderrelated differences in slowing colonic by a 5-HT3 antagonist in subjects with diarrhea-predominant IBS. Am J Gastroenterol 2001;96:2671-6.

16. Center for Drug Evaluation and Research, U.S. Food and Drug Administration. Adverse event reporting system (AERS). Available at: http://www. Fda/gov/cder/aers/ default.htm.

17. GlaxoSmithKline. Lotronex (alosetron hydrochloride tablets). Briefing document for the Joint Gastrointestinal Drugs Advisory Committee and Drug Safety and Risk Management Sub-Committee. April 23, 2002. Rockville, MD: U.S. Food and Drug Administration.

18. GlaxoSmithKline. Lotronex (alosetron hydrochloride tablets). Briefing document for the Joint Gastrointestinal Drugs Advisory Committee and Drug Safety and Risk Management Sub-Committee. May 5, 2004. Rockville, MD: U.S. Food and Drug Administration.

19. Camilleri M, Chey WY, Mayer EA, et al. A randomized controlled trial of the serotonin type 3 antagonist alosetron in women with diarrhea-predominant IBS. Arch Intern Med 2001;161:1733-40.

20. Wolfe S, Chey W, Washington MK, et al. Tolerability of the 5HT3 receptor antagonist alosetron following long-term administration in female and male IBS patients. Am J Gastroenterol 2001;96:803-11.

21. Talley N, van Zanten S, Dukes G, et al. A dose ranging, randomized, placebo-controlled, clinical trial of alosetron in subjects with functional dyspepsia. Aliment Pharmacol Ther 2001;15(4):525-37.

22. Cremonini F, Delgardo-Aros S, Camilleri M. Efficacy of alosetron in IBS: A meta-analysis of randomized controlled trials. Neurogastroenterol Motil 2003:15:7986.

23. Higgins PDR, Davis KJ, Laine L. Systematic review: The epidemiology of ischemic colitis. Aliment Pharmacol Ther 2004;19:729-38.

24. Walker AM, Bohn RL, Cali C, et al. Risk factors for colon ischemia. Am J Gastroenterol 2004;99:1333-7.

25. Singh G, Mithal A, Triadafilopoulos G. Patients with irritable bowel syndrome have a high-risk of developing ischemic colitis [abstract]. Gastroenterology 2004;126:A349.

26. Cole JA, Cook SF, Sands BE, et al. Occurrence of colon ischemia in relation to irritable bowel syndrome. Am J Gastroenterol 2004;99:486-91.

27. Brinker A, Senior J, Beitz J. Misdiagnosis of ischemic colitis as irritable bowel syndrome [abstract]. Clin Pharmacol Ther 2003;73:P33.

28. American Gastroenterological Association. The burden of gastrointestinal diseases. Bethesda, MD: AGA Press, 2001: 27-9.

29. Coates MD, Mahoney CR, Linden DR, et al. Molecular defects in mucosal serotonin content and decreased serotonin reuptake transporter in ulcerative colitis and irritable bowel syndrome. Gastroenterology 2004;126:1657-64.

30. Beck IT. Possible mechanisms for ischemic colitis during alosetron therapy. [letter] Gastroenterology 2001;121:2312.

31. Vanner S. Myenteric neurons activate submucosal vasodilator neurons in guinea pig ileum. Am J PhysiolGastrointest Liver Physiol 2000;279:G380-7.

32. Miller DP, Alfredson T, Cook S, et al. Incidence of colonic ischemia, hospitalized complications of constipation, and bowel surgery in relation to use of alosetron hydrochloride. Am J Gastroenterol 98:1117-22. 